\title{
EFFECTS OF SURFACE CHEMISTRY AND PROTEIN COMPETITIVE ADSORPTION ON CELL ADHESION
}

\author{
P. Q. Ying, G. Jin, Z. L. Tao \\ Institute of Mechanics, Chinese Academy of Sciences, Beijing, China
}

\begin{abstract}
The competitive adsorption between collagen and bovine serum albumin (BSA) was investigated by imaging ellipsometry. The competitive adsorption of the binary solution depended on the surface chemistry of substrates. At the range of concentration investigated, collagen preferentially adsorbed on the hydroxy surface (-OH surface) but BSA on the methylic surface (- $\mathrm{CH}_{3}$ surface). $\mathrm{ROS} 17 / 2.8$ cell adhesion on the two kinds of surfaces with or without the pre-adsorption of protein was also investigated. The results showed that the competitive adsorption caused ROS 17/2.8 cells preferentially adhered and spread well on the $-\mathrm{OH}$ surface, but less adhered and didn't spread on the $-\mathrm{CH}_{3}$ surface.

Keywords - Protein competitive adsorption, surface chemistry, cell adhesion, imaging ellipsometry
\end{abstract}

\section{INTRODUCTION}

The control of the adhesion of anchorage dependent mammalian cells to biomaterials is one of the key issues in tissue engineering [1]. The initial interaction of a biomaterial with a biological environment is the adsorption of proteins. It is generally accepted that cell adhesion process is mediated by specific interaction between the extracellular matrix (ECM) proteins at the substrate surface and integrin receptors of the cell surface $[2,3]$, the presence of ECM proteins on substrate surface can generally promote cell adhesion. Proteins competitive adsorption between ECM proteins and other proteins may affect the subsequent cell adhesion and other cell functions. Furthermore, protein adsorption is an important factor involved in pharmaceutical and food industries. It is necessary to investigate the competitive adsorption of proteins and its effect on other aspects.

Imaging ellipsometry is a powerful tool for visualization of the lateral thickness distribution of protein adsorption layers on surfaces without labeling. The method has a high sensitivity to thin molecular layers and high spatial resolution $(\sim 1 \mu \mathrm{m}$ laterally and $0.1 \mathrm{~nm}$ vertically). There is a linear relationship between the square root of the intensity and the surface concentration of the proteins or the thickness of the protein adsorption layer $[4,5]$. The thickness of monolayer and adsorption amount could be shown in image with different intensity in gray-scale. In this work, imaging ellipsometry was used to visualize the protein competitive adsorption, and the effects of surface chemistry and protein adsorption on cell adhesion were also investigated.

\section{METHODOLOGY}

1) Substrate preparation and modification In this research, a series of small pieces of silicon wafer $\left(7 \times 20 \mathrm{~mm}^{2}\right)$ with a natural silicon dioxide layer on optically polished surface was used as substrates for protein adsorption and then measured with imaging ellipsometry. Glass wafers were used for protein adsorption also, and then for cell adhesion. The wafer surface was chemically washed in both TL1 solution $\left(\mathrm{H}_{2} \mathrm{O}: 30 \% \mathrm{H}_{2} \mathrm{O}_{2}: 25 \% \mathrm{NH}_{4} \mathrm{OH}=5: 1: 1\right)$ and TL2 solution $\left(\mathrm{H}_{2} \mathrm{O}: 30 \% \mathrm{H}_{2} \mathrm{O}_{2}: 37 \% \mathrm{HCl}=6: 1: 1\right)$. Through the reaction of TL1 and TL2 with basic and acid solution and oxidation of hydrogen peroxide, it not only removed contaminants of the silicon surface, but also improved the number of silanol groups on the surface thus making surface hydrophilic. The surfaces were termed as $-\mathrm{OH}$ surfaces. The $\mathrm{CH}_{3}$ surface was prepared by further silanization of the hydrophilic surface. After rinsed in distilled water and ethanol, the $-\mathrm{OH}$ surface was incubated in mixture of dichlordimethylsilane $(20 \%, \mathrm{v} / \mathrm{v})$ and $\mathrm{C}_{2} \mathrm{HCl}_{3}(80 \%)$, followed by rinsing in sequence in ethanol and $\mathrm{C}_{2} \mathrm{HCl}_{3}$. Through reaction of dichlordimethylsilane with silanol groups of the surface, $-\mathrm{Si}\left(\mathrm{CH}_{3}\right)_{2}$ was immobilized covalently forming a layer of densely packed methyl groups on silicon dioxide layer to result in highly hydrophobic surface. All chemicals used were of analytical grade. As for cell adhesion, glass wafers were used as substrates and the surface modification method was the same as for the silicon wafers.

2) Protein competitive adsorption: The binary solutions containing collagen $(0.1 \mathrm{mg} / \mathrm{ml})$ and BSA $(0,1,10,50,100$, $1000 \mu \mathrm{g} / \mathrm{ml}$ ) in PBS were used for competitive adsorption. The $-\mathrm{OH}$ or $-\mathrm{CH}_{3}$ wafers were incubated in protein solutions for $30 \mathrm{~min}$, washed with PBS, dried with nitrogen, then measured for adsorption thickness with imaging ellipsometry.

In order to detect the competitive adsorption between collagen and BSA, the silicon wafers with BSA and collagen co-adsorption layer were immersed in anti-BSA solution for $30 \mathrm{~min}$. Based on the specific interaction between BSA and anti-BSA, anti-BSA in the solution bound with BSA in the layer to form protein complex of BSA/anti-BSA, and resulted in an increase of layer thickness. The more BSA adsorbed from the binary solution, the more the layer thickness increase was introduced by anti-BSA bound with BSA in the layer. In this way the amount of BSA adsorbed from the binary solution could be deduced from the thickness increase introduced by the protein complex, so as to determine the effect of the existence of BSA on collagen adsorption onto both $-\mathrm{OH}$ and $-\mathrm{CH}_{3}$ surfaces.

As for cell adhesion on glass substrates, protein adsorption with single protein of collagen $(0.1 \mathrm{mg} / \mathrm{ml}$ in PBS) or BSA ( $1 \mathrm{mg} / \mathrm{ml}$ in PBS) was also used besides the binary solution of collagen and BSA. The adsorption or competitive adsorption time was $2 \mathrm{~h}$.

3) Imaging ellipsometry measurement: Imaging ellipsometry is used for quantification and visualization of the thickness distribution of protein adsorption layer on 
substrates. The method is based on the use of combined null and off-null ellipsometry at an incident angle close to the pseudo-Brewster angle of the substrate, with the chargecoupled device (CCD) as a photodetector for imaging. An image of $15 \times 25 \mathrm{~mm}^{2}$ of a surface is focused onto a CCD video camera for intensity measurements. The video signal corresponding to the thickness distribution is captured, digitized and stored in gray-scale format in a computer. There is a linear relationship between the square root of the intensity and the surface concentration of the proteins or the thickness of the protein adsorption layer. The thickness of protein adsorption layers or the surface concentration of adsorbed protein is shown in gray scale. As for the same protein and under the same ellipsometric condition, the value of 'gray scale increases with the increase of protein surface concentration. After a protein adsorption layer forming onto a substrate, the substrate can be immersed in a second protein solution where the protein in the solution can interact specifically with the protein on the surface (such as antigenantibody and receptor-ligand) resulting in a protein complex layer. The thickness distributions in grayscale of the adsorption layer and the complex layer can be directly visualized by imaging ellipsometry. In this research, in order to investigate the protein competitive adsorption, the imaging technique was used to visualize the co-adsorption layer of collagen and BSA on the two surfaces, and then the complex layer of anti-BSA/BSA after the co-adsorption layer: was incubated in anti-BSA solution.

4) Cell culture and adhesion: ROS 17/2.8 osteosarcoma cells were employed for cell adhesion. Cultures were maintained in a $37^{\circ} \mathrm{C}$ water-jacketed incubator equilibrated with $5 \% \mathrm{CO}_{2}$ and kept at approximately $99 \%$ relative humidity. The cells were incubated in Dulbecco's modified Eagle's medium (DMEM) supplemented with $10 \%(\mathrm{v} / \mathrm{v})$ fetal bovine serum (Hyclone) and $100 \mathrm{U} / \mathrm{ml}$ penicillin and streptomycin on a $250-\mathrm{ml}$ plastic culture flask (Costar). The sub-culturing of cells was conducted at $4-5$ days intervals with trypsin-EDTA (Hyclone).

The $-\mathrm{OH}$ and $-\mathrm{CH}_{3}$ glass wafers with or without preadsorbed protein were used for cell adhesion. The cultured cells were trypsinized from the culture flasks and suspended in DMEM. DMEM without fetal bovine serum was used for the substrates pre-prepared without protein adsorption, or with the adsorption of BSA, collagen, binary solution of BSA and collagen, respectively. To investigate the effects on cell adhesion of the competitive adsorption of proteins in serum, DMEM with $10 \%$ fetal bovine serum was also used for the substrates without protein adsorption. Cells were plated on the surfaces at a density of $1 \times 10^{5} / \mathrm{cm}^{2}$. After incubation for 2 $\mathrm{h}$, nutritive media were removed. The wafers were rinsed with $2 \mathrm{ml}$ PBS to remove non-adherent cells. The adherent cells were trypsinized and numbered with a haemacytometer. The cell adhesion rate was defined as the percentage of adhered cells to the plated cells. The results were averaged of three parallel tests. The cell adhesion was also photographed with the CCD connected to a microscope (Olympus, Japan) before trypsinization.
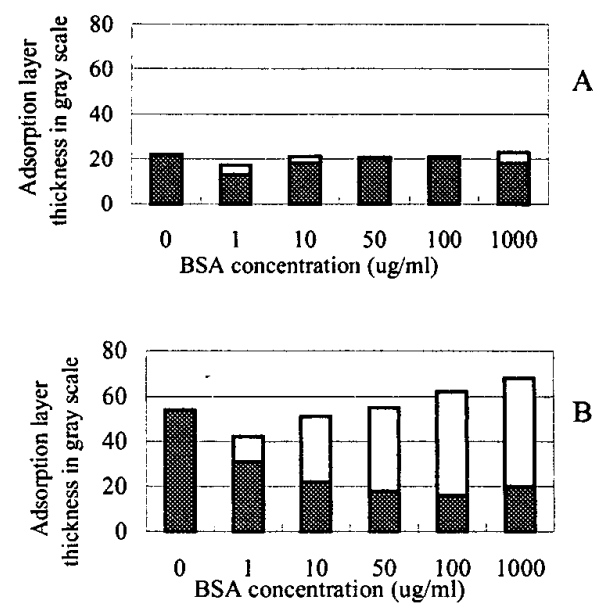

Fig. 1. Adsorption layer thickness for the competitive adsorption between $\mathrm{BSA}$ and collagen on the $-\mathrm{OH}(\mathrm{A})$ and $-\mathrm{CH}_{3}(\mathrm{~B})$ surfaces

( The co-adsorption layer of BSA and collagen, $\square$ the thickness variation introduced by the protein complex of BSA/anti-BSA).

\section{A. Protein competitive adsorption}

Fig.1 showed the average thickness in gray-scale of adsorption layers for protein competitive adsorption on - $\mathrm{OH}$ and $-\mathrm{CH}_{3}$ surfaces. On the $-\mathrm{CH}_{3}$ surface, the thickness of coadsorption layer of collagen and BSA decreased obviously as an appearance of BSA, but the thickness variation introduced by the protein complex of BSA/anti-BSA increased with the increase of BSA concentration. After the concentration of BSA reached $100 \mu \mathrm{g} / \mathrm{ml}$, the thickness of the two layers varied slightly with the increase of BSA concentration (fig. 1B) On the -OH surface, the thickness variation introduced by the protein complex was not obvious (fig. 1A), and the thickness of the co-adsorption layer decreased less than on $\mathrm{CH}_{3}$ surface.

It is known that collagen (molecular mass of about 300 , 000 ) is a triple helix about $300 \mathrm{~nm}$ long and $1.5 \mathrm{~nm}$ in diameter but BSA is much smaller with molecular mass about 66,200 . Compared with pure collagen solution, adsorption from mixed protein solution of collagen and BSA on $-\mathrm{CH}_{3}$ surfaces resulted in a sharp decrease in thickness of the coadsorption layer even at a low BSA concentration $(10 \mu \mathrm{g} / \mathrm{ml})$. On the -OH surface, the thickness of the co-adsorption layer was also decreased, but less. The possibilities that led to the less anti-BSA combination might be the less BSA on the coadsorption layer or the conformation change of BSA that resulted in the failure combination of anti-BSA with BSA. In order to exclude the possibility that adsorption of BSA on surfaces might change the conformation of BSA making the detection by anti-BSA inaccessible, pure BSA solution was used to form the BSA adsorption layer and detected by antiBSA. The results showed the method was accessible on both of the surfaces (data not shown). The competitive adsorption of collagen and BSA on the two surfaces resulted in that 
collagen adsorbed mostly on the $-\mathrm{OH}$ surfaces and BSA on the $-\mathrm{CH}_{3}$ surfaces.

Further to show the phenomenon, silicon wafer with $-\mathrm{CH}_{3}$ on the left end and $-\mathrm{OH}$ on the right end, that is, silicon wafer with both kinds of chemically modified surfaces, was incubated with binary protein solution of BSA $(1 \mathrm{mg} / \mathrm{ml})$ and collagen $(0.1 \mathrm{mg} / \mathrm{ml})$ for $30 \mathrm{~min}$, washed with PBS, incubated in anti-BSA solution for $30 \mathrm{~min}$. Fig. 2 showed the gray-scale variation of silicon wafer surface visualized with imaging ellipsometry before competitive adsorption (A), after competitive adsorption (B) and after the interaction of antiBSA and BSA (C). It was shown that after competitive adsorption of collagen and BSA, the adsorption layer on the $\mathrm{OH}$ surface was thicker than that on the $-\mathrm{CH}_{3}$ surface, that is, the surface concentration of protein was higher on the $-\mathrm{OH}$ surface. After the interaction of BSA with anti-BSA, the adsorption layer rose obviously on the $-\mathrm{CH}_{3}$ surface, but varied little on the $-\mathrm{OH}$ surface, indicating little BSA/antiBSA complex formed on the $-\mathrm{OH}$ surface. Combining the results showed in fig. 1 and fig. 2 , it would be sure that competitive adsorption of collagen and BSA on the two surfaces resulted in that collagen preferentially adsorbed on the - $\mathrm{OH}$ surface and BSA on the $-\mathrm{CH}_{3}$ surface.

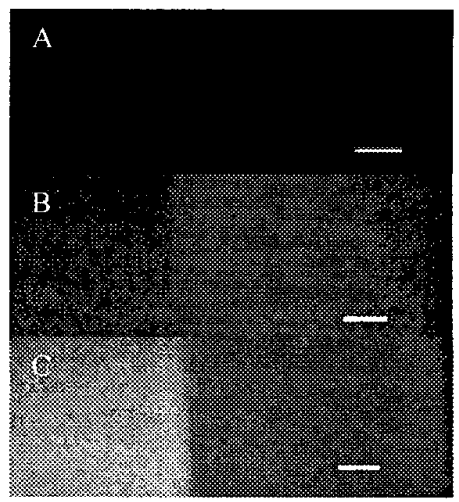

Fig. 2. Ellipsometric images showed (A) the substrate surface with the $\mathrm{CH}_{3}$ region (left) and $-\mathrm{OH}$ region (right); (B) the competitive adsorption of collagen and BSA on the surface; (C) the anti-BSA and BSA interaction result after the surface incubated in anti-BSA solution. Scale bar is $2 \mathrm{~mm}$.

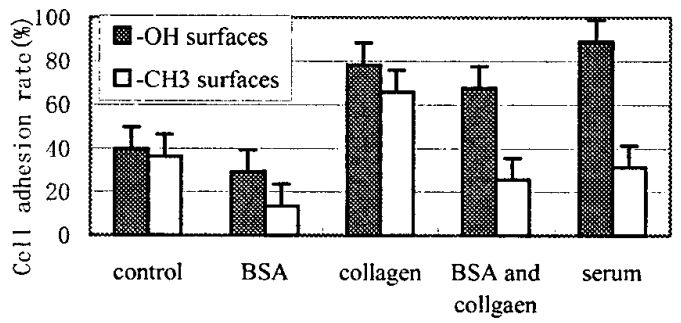

Fig 3. ROS 17/2.8 cells adhesion on $-\mathrm{OH}$ and $-\mathrm{CH}_{3}$ surfaces after $2 \mathrm{~h}$ incubation. Surfaces were incubated in BSA, collagen, and binary solution of collagen and BSA for protein adsorption, respectively, before the cell adhesion. The surfaces without protein adsorption were used as reference. Cell adhesion on surfaces without protein adsorption were also investigated in the incubation media supplemented with $10 \%$ fetal bovine serum, and other conditions were kept the same.

\section{B. Cell adhesion and spread}

Fig. 3 showed ROS 17/2.8 cell adhesion rate on the two surfaces with or without pre-adsorbed proteins after $2 \mathrm{~h}$ incubation. Cell adhesion slightly differed between the two surfaces without pre-adsorbed proteins. Surfaces pre-coated with BSA inhibited cell adhesion, especially on the $-\mathrm{CH}_{3}$ surface, the cell adhesion rate was the lowest. On the contrary, collagen promoted cell adhesion on both surfaces and cell adhesion rate on the $-\mathrm{OH}$ surface was slightly higher than that on the $-\mathrm{CH}_{3}$ surface. Fig. 3 also showed that when surfaces were pre-adsorbed with the binary solution of collagen and $\mathrm{BSA}$, cell adhesion rate on the -OH surface was much higher than that on the $-\mathrm{CH}_{3}$ surface, which confirmed the effect of protein competitive adsorption on cell adhesion. Preferential adsorption of collagen on the -OH surface promoted cell adhesion, while adsorption of BSA on the $-\mathrm{CH}_{3}$ surface did not. Photographs in fig. 4 showed the cell adhesion and spread after $2 \mathrm{~h}$ incubation on the two surfaces pre-adsorbed with the binary solution. ROS $17 / 2.8$ cells spread well on the $-\mathrm{OH}$ surface (fig. 4A), while hardly spread on the $-\mathrm{CH}_{3}$ surface (fig. 4B).

When cells were cultured in media with serum which containing high concentrations of albumin and low concentration of ECM protein such as fibronectin, protein competitive adsorption might affect cell adhesion resulting in cells adhering more on - $\mathrm{OH}$ surfaces than on $-\mathrm{CH}_{3}$ surfaces, as was shown in fig. 3 . The protein competitive adsorption affected cell adhesion directly.

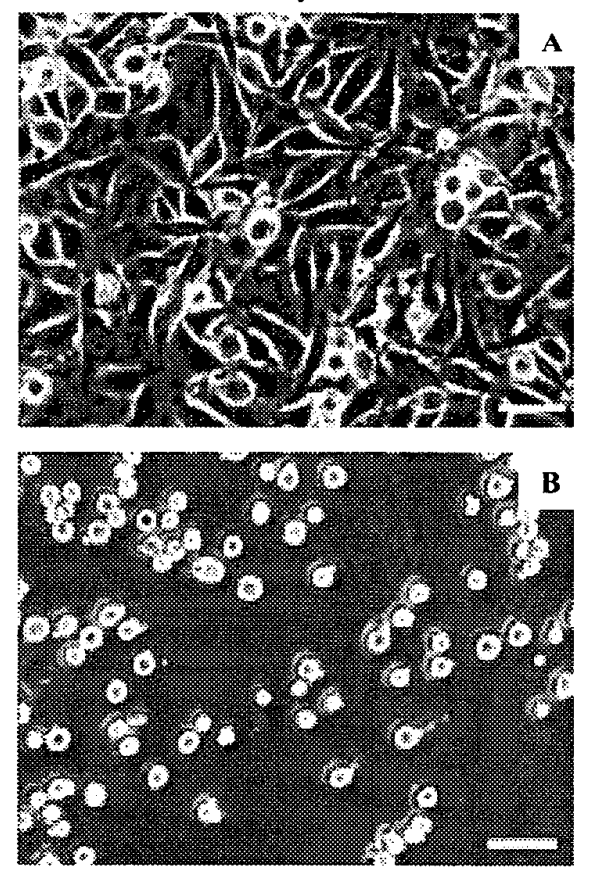

Fig 4 ROS 17/2.8 cells adhesion and spread on -OH surface (A) and $-\mathrm{CH}_{3}$ surface (B) after $2 \mathrm{~h}$ incubation. Before the cell adhesion the two kinds of surfaces were incubated with the binary protein solution of collagen and BSA for $2 \mathrm{~h}$. Scale bar is $50 \mu \mathrm{m}$. 


\section{CONCLUSION}

In this research, imaging ellipsometry was employed as a simple and efficient tool for the investigation of protein competitive adsorption.

Protein competitive adsorption between BSA and collagen showed that BSA preferentially adsorbed onto $-\mathrm{CH}_{3}$ surface, but collagen preferentially adsorbed on - $\mathrm{OH}$ surface.

The competitive adsorption resulted in ROS 17/2.8 cells preferentially adhering and spreading well on the $-\mathrm{OH}$ surface, but less adhering and no spreading on the $-\mathrm{CH}_{3}$ surface.

\section{ACKNOWLEDGMENT}

The authors are grateful to Z. H. Wang and Y. H. Meng for their help in bio-molecule manipulation and imaging ellipsometry performance. Chinese Academy of Sciences is acknowledged for its support.

\section{REFERENCES}

[1] J.L. Dewez, J.B. Lhoest, E. Detrait, V. Berger, C.C. Dupont-Gillain, L.M. Vincent, Y.J. Schneider, P. Bettrand, P.G. Rouxhet, "Adhesion of mammalian cells to polymer surfaces: from physical chemistry of surfaces to selective adhesion on defined patterns," Biomaterials, vol. 19, pp. 1441-1445, 1998.

[2] R.O. Hynes, "Integrins: versatility, modulation, and signaling in cell adhesion," Cell, vol. 69, pp. 11-25, 1992.

[3] S.K. Akiyama, S.E. LaFlamme, "Bioadhesion and cell behavior," Colloids Surf. B Biointerf., vol. 2, pp. 241-250, 1994.

[4] H. Arwin, S. Welin-Klintström, R. Jansson, "Off-null ellipsometry revisited: basic considerations for measuring surface concentrations at solid/liquid interfaces," J. Colloid Interface Sci., vol. 156, pp. 377-382, I993.

[5] G. Jin, P. Tengvall, I. Lundströnm, H. Arwin, "A biosensor concept based on imaging ellipsometry for visualization of biomolecular interactions," Analytical Biochemistry, vol. 232, pp. 69-72, 1995. 